\title{
SINERGITAS ANTARA PEMANDU WISATA DAN OPERATOR TUR (Study Kasus di CV Gondes Karya Mandiri)
}

\author{
I Putu Hardani HD \\ STP AMPTA Yogyakarta, iputu.hardani@gmail.com
}

\begin{abstract}
ABSTRAK
Pemandu wisata dengan Operator Tur merupakan dua hal yang tidak bisa dipisahkan dalam pelaksanaan paket wisata. Sehingga koordinasi diantara kedua bagian ini sangat diperlukan agar paket wisata yang dijual dapat berjalan lancar. Penelitian ini bertujuan untuk mengetahui hubungan yang saling berkaitan satu dengan yang lainnya. Metode Penelitian yang digunakan yaitu penelitian kualitatif tentang Sinergitas Antara Pemandu Wisata Dan Operator Tur di CV Gondes Karya Mandiri, data dianalisa dari 16 pemandu wisatadan 5 eksekutif operator tur dengan menganalisa 15 atribut. Hasil penelitian menyebutkan bahwa pemandu wisata dan opearatur tur saling bekerjasama dengan sinergi meskipun ada sedikit perbedaan persepsi namun tetap bisa berjalan dan bekerjasama dengan baik. Saran dari hasil penelitian ini memberikan rekomendasi untuk memberikan pembeda pada penggajian. Selain itu juga memberikan rekomendasi pada penelitian selanjutnya untuk meneliti tingkat kepuasan pelayanan pemandu wisata dengan Operator Tur.
\end{abstract}

Kata Kunci : Pemandu Wisata, Operator Tur, Paket Wisata, Sinergitas

\section{ABSTRAK}

Tour guide with Tour Operator are two things that can not be separated in the implementation of tour packages. So that coordination between these two parts is necessary so that the tour packages sold can sucsesfull. This study aims to find out the relationships that are interrelated with each other. The research method used is qualitative research on synergy between tour guides and tour operators at CV Gondes Karya Mandiri, data analyzed from 16 tour guides and 5 executive tour operators by analyzing 15 attributes. The results of the study mentioned that tour guides and tour operators cooperate with each other with synergy although there is a slight difference in perception but still can run and cooperate well. Suggestions from the results of this study provide recommendations to provide differentiation on payroll. In addition, it also provides recommendations on further research to examine the level of satisfaction of tour guide services with Tour Operators.

Keywords : Tour Guide, Tour Operator, Tour Packages, Synergy

\section{PENDAHULUAN}

Dalam aktivitas pariwisata banyak steakholder yang terlibat dalam pelaksanaan dilapangan seperti akomodasi, operasional Tur, jasa pemandu wisata, transportasi, rekreasi, jasa boga/ catering, maupun atraksi wisata dan budaya. Semua komponen yang ada dalam hal ini sering dikenal dengan istilah Paket Wisata.
Dengan menggunakan jasa paket wisata, maka perjalanan yang dilakukan wisatawan akan terorganisir dengan baik dan terperinci. Namun dalam kegiatan palaksanaan berwisata, banyak yang mengartikan bahwa Pemandu Wisata sekaligus merangkap sebagai Operatur Tur. Oleh karena itu, studi ini bertujuan untuk menganalisis kualitas pemandu dan 
layanan pemandu dari perspektif operator tur dan pemandu serta mengeksplorasi perbedaan persepsi masing-masing dari kedua pemangku kepentingan yang saling bergantung ini.

\section{KAJIAN LITERATUR}

A guided tur is a convenient product that enables turists to visit and comprehend the destination characteristics with relative ease in a short time at low cost (Cohen, Ifergan, \& Cohen, 2002). Pemandu wisata bertujuan melalui penyampaian pengetahuan tentang budaya, sejarah, makna, narasi dan gambar daerah serta menjelaskan semua potensi yang ada di daerah wisata yang dikunjungi wisatawan.

\section{Peran pemandu wisata dalam industri perjalanan}

Definisi pemandu wisata yang umum menyiratkan bahwa pemandu adalah karyawan profesional yang memimpin, berkomunikasi dengan dan memberi tahu pengunjung tentang tujuan dengan cara yang efisien dan menarik dalam bahasa pilihan mereka. Pemandu biasanya adalah penduduk yang memegang lisensi yang dikeluarkan oleh otoritas lokal dan bekerja atas nama perusahaan perjalanan dengan biaya, upah atau gaji (Federasi Asosiasi Pemandu Wisata Dunia: 2014).

Pemandu adalah penerjemah, pendidik, duta masyarakat tuan rumah, dan fasilitator interaksi antara budaya lokal, lokal dan wisatawan, baik asing maupun domestik. Pemandu juga merupakan pemegang dan penyedia pengetahuan, instruktur, perantara budaya, penerjemah, penghibur, aktor, pendongeng, misionaris, mentor, pencari jalan, perantara, perantara, penyangga, pengasuh, penyelenggara, penjual, gembala dan pembuat keputusan (Cohen, 1985; Dahles, 2002; Hansen \& Mossberg, 2016). Seorang pemandu sebagai pemimpin mengambil tanggung jawab untuk kelancaran tur dan kesejahteraan klien (Larsen \& Meged: 2013). Pemandu wisata biasanya merupakan orang local yang mengarahkan wisatawan untuk mengunjungi suatu obyek wisata dan memberikan penjelasan terhadap suatu obyek wisata. Tingkat karakter professional pemandu wisata dalam penyampaian informasi tentang suatu obyek wisata kepada para wisatawan, meliputi : (1) Tingkat pendekatan, meliputi perkenalan, tanyajawab dan memeberikan permainan yang seru; (2) Tingkat pengalaman, melibatkan kreativitas bagi wisatawan; (4) Tingkat ketertarikan pada suatu informasi; (5) Tingkat pengembangan, yaitu merubah pola pikir wisatawan terhadap suatu obyek wisata.

Dengan demikian, seorang pemandu wisata memiliki berbagai peran professional yang bergantung pada karakteristik wisatawan dengan model pengembangan materi pemanduan yang disampaikan. Namun dalam praktek dilapangan hal ini terjadi kendala untuk bisa mempertahankan peran tersebut yang meliputi terkendala pada hubungan yang seimbang dan harmonis antara wisatawan, operator tur, agen perjalanan, maupun pemasok jasa pelayanan yang lainnya. Berikut ini table Hubungan wewenang antara pemangku kepentingan yang berbeda dalam industri pariwisata yang mempengaruhi peran pemandu wisata dengan pemandu tur.

\section{Tabel 1. The power relations between} different stakeholders

\begin{tabular}{ll} 
Tur stakeholders & $\begin{array}{l}\text { Tur guide roles } \\
\text { Interpreter, instructor, } \\
\text { leader, educator, } \\
\text { entertainer, etc. }\end{array}$ \\
Visitors, turists & $\begin{array}{l}\text { Employee, } \\
\text { representative, } \\
\text { organizer, manager, etc. }\end{array}$ \\
Visitors, turists & $\begin{array}{l}\text { Coordinator, } \\
\text { entrepreneur, } \\
\text { salesperson, } \\
\text { intermediary, etc. }\end{array}$ \\
Turism service & $\begin{array}{l}\text { Representative, } \\
\text { ambassador, facilitator, } \\
\text { middleman, etc. }\end{array}$ \\
\hline $\begin{array}{l}\text { Destination, locals } \\
\text { Tur stakeholders }\end{array}$ & Tur guide roles \\
\hline $\begin{array}{l}\text { Sumber: Adopted from Cohen (1985). } \\
\text { Pemandu wisata bertanggung jawab untuk } \\
\text { melaksanakan jadwal tur / itinerary } \\
\text { dengan lancar atas }\end{array}$ \\
$\begin{array}{ll}\text { (Mak et al., 2011). Peran pemandu wisata } \\
\text { instrumental antara lain }\end{array}$ \\
\hline
\end{tabular}


mengorientasikan, mengarahkan, dan melakukan tur, mengatur jadwal dan kecepatannya, mengarahkan pengunjung ke obyek wisata, menjaga kenyamanan dan keselamatan wisatawan, serta menjaga anggota kelompok wisata. Menurut Tjiptono (2014 : 268) definisi "Kualitas Pelayanan berfokus pada upaya penemuan kebutuhan dan keinginan konsumen serta ketepatan penyampaian untuk mengimbangi harapan konsumen. Sementara untuk dimensi Kualitas Pelayanan Pramuwisata menurut Huang et. al (2010 : 5) yaitu sebagai berikut: (1) Professional Competence;

Interpersonal Skills; (3) Organization Skills; (4) Emphaty; (5) Problem Solving.

Berdasarkan ke 5 dimensi tersebut maka ketrampilan seorang pemandu wisata memang sangat penting harus dikuasai sehingga mampu mengakomodir kebutuhan wisatawan di lapangan.

\section{Sinergitas Antara Pemandu Wisata dan Operator Tur}

Dalam pelaksanaan tur, seorang pemandu wisata tidak akan lepas dengan kinerja dari Operator Tur. Operatot tur menjadi sangat penting dalam mencari, memasarkan produk paket wisata yang akan dilaksanakan oleh pemandu wisata. Pemandu wisata bekerja berdasarkan tugas dari operator tur, sehingga harus selalu berkomunikasi secara berkelanjutan ketika melaksanakan program wisata. tur operators are very much dependent on guides for the creation of an enriching holiday experience (Jonasson \& Scherle, 2012).

Pelaksanaan Tur sangat bergantung pada kecakapan pemandu wisata dalam menjalankan kegiatan dilapangan, sehingga Operator Tur terkadang tidak mampu mengontrol jalannya kegiatan yang ada di lapangan. Hal ini menjadi kendala bagi operator tur untuk mengetahui apakah tur guide tersebut melaksanakan tugas dilapangan berdasarkan SOP perusahaan atau tidak melaksanakan. Kendala ini akan terus berlanjut jika tidak ada upaya untuk memberikan perbaikan dalam koordinasi maupun komunikasi dengan baik.
Disisi lain, untuk pendapat bagi seorang pemandu wisata masih dirasa sedikit jika dibandingkan seorang tur operator, hal ini yang menjadi salah satu perhatian bagi pihak biro perjalanan wisata untuk memberikan tambahan pendapatan bagi pemandu wisata. Tugas pemandu wisata yang berat dilapangan karena harus mengkondisikan wisata dalam berbagai keadaan di lapangan agar program yang diberikan seorang tur operator berjalan dengan lancar.

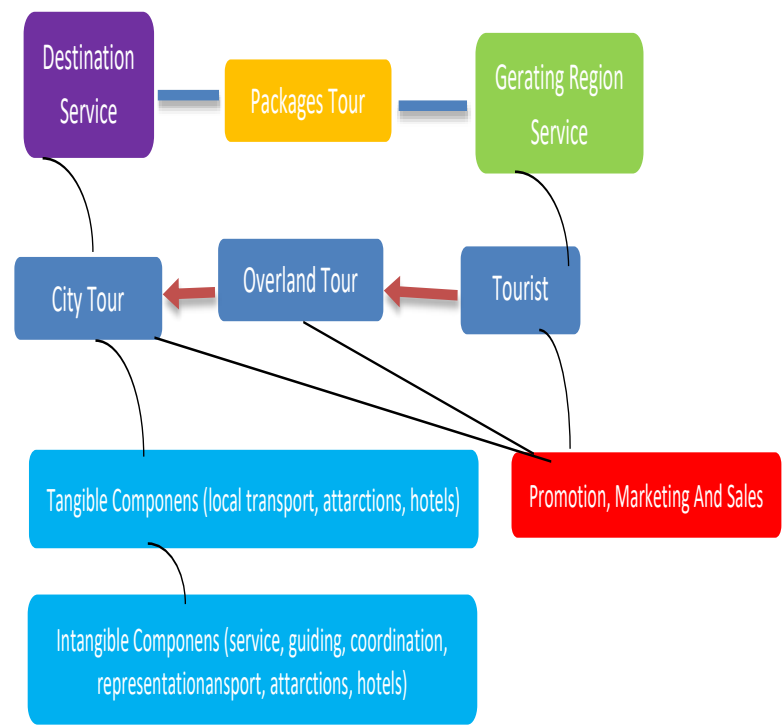

Gambar 1. Package tur production and distribution system

Sumber : CV Gondes Karya Mandiri

\section{METODE PENELITIAN}

Metode Penelitian yang digunakan yaitu penelitian kualitatif tentang Sinergitas Antara Pemandu Wisata Dan Operator Tur di CV Gondes Karya Mandiri sehingga akan menghasilkan rekomendasi terbaik bagi biro perjalanan wisata $\mathrm{CV}$ Gondes Karya Mandiri. Teknik Analisis yang pertama dalam proses ini adalah melakukan inventarisasi, klasifikasi dan evaluasi terhadap kinerja pemandu wisata dan operator tur.

Pengumpulan data dilakukan selama Oktober 2019 sampai dengan April 2020. Tahap kedua, total 16 wawancara mendalam dilakukan dengan pemandu wisata dan 5 eksekutif Operator Tur, hal ini untuk mengidentifikasi kualitas penting pemandu wisata dan operator tur. Tahap eksplorasi kualitatif berlanjut sampai 
kejelasan data tercapai. Beberapa karakteristik yang sesuai dengan panduan kinerja untuk pemandu wisata diidentifikasi melalui wawancara.

Tahap terakhir, pra-tes untuk validitas diberikan pada 16 pemandu wisata dan 5 eksekutif operator tur. Proses triangulasi ini digunakan untuk meningkatkan kelayakan kepercayaan penelitian. Hasilnya dibandingkan dan kesepakatan dari dimensi panduan tercapai. Beberapa penyesuaian dilakukan; beberapa pertanyaan disusun dan beberapa atribut dihapus atau digabungkan. Akhirnya, 15 atribut ditentukan untuk merancang 2 kuesioner; satu untuk pemandu wisata dan yang lainnya untuk operator tur dalam BPW.

\section{PEMBAHASAN}

Berdasarkan hasil wawancara dan pengamtan yang dilakukan dilapangan, berikut ini hasilnya.

Tabel 2 Data CV Gondes Karya

\begin{tabular}{|c|c|c|}
\hline \multicolumn{3}{|c|}{ Mandiri } \\
\hline $\begin{array}{l}\text { KOMP } \\
\text { ONEN }\end{array}$ & $\begin{array}{l}\text { PEMANDU } \\
\text { WISATA }\end{array}$ & $\begin{array}{c}\text { OPERATOR } \\
\text { TUR }\end{array}$ \\
\hline $\begin{array}{l}\text { Educatio } \\
\text { n level }\end{array}$ & $\begin{array}{l}\text { Responden rata- } \\
\text { rata memiliki } \\
\text { tingkat } \\
\text { Pendidikan } \\
\text { menengah dan } \\
\text { sarjana. Selain } \\
\text { itu setiap } \\
\text { pemandu wisata } \\
\text { yang akan } \\
\text { melaksnakan } \\
\text { tugas } \\
\text { dilapangan } \\
\text { selalu diperiksa } \\
\text { legalitas } \\
\text { kompetensi dari } \\
\text { pemandu wisata } \\
\text { itu sendiri, } \\
\text { sehingga Ketika } \\
\text { dilapngan akan } \\
\text { mampu } \\
\text { menjalankan } \\
\text { tugas dengan } \\
\text { aman dan } \\
\text { terarah sesuai } \\
\text { dengan } \\
\text { peraturan yang } \\
\text { ada. }\end{array}$ & $\begin{array}{l}\text { Para pekerja } \\
\text { memiliki latar } \\
\text { belakang } \\
\text { Pendidikan } \\
\text { diploma dan } \\
\text { sarjana. Rata- } \\
\text { rata telah } \\
\text { melalui } \\
\text { Pendidikan } \\
\text { orientasi pada } \\
\text { masa sebelum } \\
\text { kerja sehingga } \\
\text { mampu } \\
\text { menyesuaikan } \\
\text { dengan kondisi } \\
\text { yang berlaku } \\
\text { didalam } \\
\text { perusahaan. }\end{array}$ \\
\hline $\begin{array}{l}\text { Commun } \\
\text { ication }\end{array}$ & $\begin{array}{l}\text { Responden } \\
\text { memiliki }\end{array}$ & $\begin{array}{l}\text { Responden } \\
\text { memiliki }\end{array}$ \\
\hline
\end{tabular}

\begin{tabular}{|c|c|c|}
\hline skills & $\begin{array}{l}\text { ketrampilan } \\
\text { berkomunikasi } \\
\text { yang bagus dan } \\
\text { mudah } \\
\text { dipahami. } \\
\text { Komunikasi } \\
\text { menjadi hal } \\
\text { yang terpenting } \\
\text { dalam } \\
\text { pemanduan } \\
\text { wisata karena } \\
\text { Ketika bertugas } \\
\text { seorang } \\
\text { pemandu wisata } \\
\text { bukan hanya } \\
\text { memiliki } \\
\text { pengetahuan } \\
\text { yang mendasar } \\
\text { dan up date } \\
\text { tetapi juga } \\
\text { mampu } \\
\text { mentransfer } \\
\text { ilmu yang } \\
\text { dimiliki menjadi } \\
\text { sebuah } \\
\text { komunikasi } \\
\text { yang menarik } \\
\text { dan mudah } \\
\text { dipahami bagi } \\
\text { para wisatwan. } \\
\text { Dengan } \\
\text { komunikasi } \\
\text { yang terbaik ini } \\
\text { maka wisatwan } \\
\text { akan memiliki } \\
\text { ingatan yang } \\
\text { terhadap } \\
\text { moment Ketika } \\
\text { melakukan } \\
\text { perjalanan } \\
\text { wisata dan akan } \\
\text { datang Kembali } \\
\text { (memakai jasa } \\
\text { Biro perjalanan } \\
\text { ini) }\end{array}$ & $\begin{array}{l}\text { ketrampilan } \\
\text { cukup baik. Hal } \\
\text { ini berdsarkan } \\
\text { wawancara dan } \\
\text { observasi yang } \\
\text { dilakukan } \\
\text { dilapangan } \\
\text { dengan } \\
\text { pembuktian dan } \\
\text { respon yang } \\
\text { baik bukan saja } \\
\text { pada saat } \\
\text { menawarkan } \\
\text { paket wisata } \\
\text { namun juga } \\
\text { dalam } \\
\text { menyampaikan } \\
\text { informasi apa } \\
\text { saja yang } \\
\text { diperlukan } \\
\text { pwemandu } \\
\text { wisata saat } \\
\text { dilapangan. } \\
\text { Informasi dalam } \\
\text { komunikasi ini } \\
\text { berkaitan } \\
\text { dengan jumlah } \\
\text { pax, itternerary } \\
\text { maupun } \\
\text { peralatan apa } \\
\text { saja yang harus } \\
\text { dipersiapan } \\
\text { maupun harus } \\
\text { dibawa baik } \\
\text { pemandu wisata } \\
\text { maupun } \\
\text { wisatwan yang } \\
\text { akan dipandu. }\end{array}$ \\
\hline $\begin{array}{l}\text { Foreign } \\
\text { language }\end{array}$ & $\begin{array}{l}\text { Rata rata } \\
\text { menguasai } \\
\text { Bahasa Inggris, } \\
\text { Bahasa Jepang } \\
\text { dan Bahasa } \\
\text { Perancis. } \\
\text { Pemandu wisata } \\
\text { yang berkerja } \\
\text { disini rata- rata } \\
\text { menguasai } 2 \\
\text { sampai } 3 \text { bahasa } \\
\text { sehingga pada } \\
\text { saat musim }\end{array}$ & $\begin{array}{l}\text { Hanya } \\
\text { menguasai } \\
\text { Bahasa Inggris. } \\
\text { Keterbatasan } \\
\text { Bahasa asing } \\
\text { selain Bahasa } \\
\text { inggris menjadi } \\
\text { kendala pada } \\
\text { saat melakukan } \\
\text { prmosi, } \\
\text { sehingga } \\
\text { beberapa } \\
\text { diantaranya }\end{array}$ \\
\hline
\end{tabular}

ISSN: 2355-6587, e-ISSN: 2528-2220 


\begin{tabular}{|c|c|c|c|c|c|}
\hline & $\begin{array}{l}\text { ramai sekalipun } \\
\text { tidak akan } \\
\text { kekurangan stok } \\
\text { pemandu wisata } \\
\text { yang mampu } \\
\text { berbahasa asing. } \\
\text { Selain itu } \\
\text { pemandu wisata } \\
\text { yang berkerja } \\
\text { disini sangat } \\
\text { fasih berbicara } \\
\text { Bahasa inggris } \\
\text { dan Bahasa }\end{array}$ & $\begin{array}{l}\text { selalu } \\
\text { berkoordinasi } \\
\text { dan } \\
\text { berkouminikasi } \\
\text { dengan } \\
\text { pemandu wisata } \\
\text { agar bisa sesuai } \\
\text { dengan target. }\end{array}$ & $\begin{array}{l}\text { ge } \\
\text { interpret } \\
\text { ation }\end{array}$ & $\begin{array}{l}\text { mampu } \\
\text { menginterpretasi } \\
\text { kan data dan } \\
\text { informasi } \\
\text { dengan baik } \\
\text { kepada para } \\
\text { peserta wisata } \\
\text { tanpa ada } \\
\text { kompain }\end{array}$ & $\begin{array}{l}\text { mampu } \\
\text { menginterpretas } \\
\text { ikan data dan } \\
\text { informasi } \\
\text { dengan baik } \\
\text { sehigga } \\
\text { memiliki } \\
\text { kesamaan } \\
\text { pemahaman } \\
\text { antara tur } \\
\text { operator dengan } \\
\text { pemandu wisata }\end{array}$ \\
\hline & $\begin{array}{l}\text { asing yang } \\
\text { lainnya. }\end{array}$ & & \multirow[t]{2}{*}{$\begin{array}{l}\text { Represen } \\
\text { tation } \\
\text { skills }\end{array}$} & \multirow[b]{2}{*}{$\begin{array}{l}\text { Mampu } \\
\text { merepresentasik } \\
\text { an materi dan } \\
\text { tugas dengan } \\
\text { baik. Step by } \\
\text { step dalam } \\
\text { pemanduan } \\
\text { wisata } \\
\text { dilakukan } \\
\text { dengan baik } \\
\text { sehingga } \\
\text { wisatawan } \\
\text { paham dengan } \\
\text { materi } \\
\text { pemanduan } \\
\text { yang } \\
\text { disampaikan }\end{array}$} & \multirow[b]{2}{*}{$\begin{array}{l}\text { Kemampuan } \\
\text { merepresentasik } \\
\text { an dengan baik } \\
\text { dari setiap } \\
\text { komponen } \\
\text { pemasok suatu } \\
\text { paket wisata } \\
\text { yang akan } \\
\text { dilaksanakan } \\
\text { oleh pemandu } \\
\text { wisata } \\
\text { dilapangan, } \\
\text { sehingga } \\
\text { pelaksanaan tur } \\
\text { berjalan dengan } \\
\text { lancar. }\end{array}$} \\
\hline $\begin{array}{l}\text { Personal } \\
\text { ity }\end{array}$ & $\begin{array}{l}\text { Memiliki } \\
\text { kepribadian } \\
\text { yang aik, hal ini } \\
\text { dilihat dari } \\
\text { sejarah kinerja } \\
\text { selama } \\
\text { melaksanakan } \\
\text { tugas } \\
\text { dilapangan tidak } \\
\text { ada masalah. } \\
\text { Seorang } \\
\text { pemandu wisata } \\
\text { mampu } \\
\text { memberika } \\
\text { lavanan nrima }\end{array}$ & $\begin{array}{l}\text { Kepribadian } \\
\text { yang baik. } \\
\text { Karyawan } \\
\text { operator tur } \\
\text { memiki } \\
\text { kepribadian } \\
\text { yang baik hal ini } \\
\text { terlihat dari } \\
\text { kekompakan } \\
\text { dalam bekerja } \\
\text { dan bekerjasama } \\
\text { dengan kolega } \\
\text { maupun dengan } \\
\text { pemandu wisata }\end{array}$ & & & \\
\hline & $\begin{array}{l}\text { berupa } \\
\text { personality yang } \\
\text { menarik } \\
\text { sehingga tidak } \\
\text { membuat bosan } \\
\text { bagi wisatwan } \\
\text { Ketika mereka } \\
\text { melakukan } \\
\text { pemanduan } \\
\text { wisata. }\end{array}$ & & \multirow[t]{2}{*}{$\begin{array}{l}\text { Experien } \\
\text { ce } \\
\text { creation }\end{array}$} & $\begin{array}{l}\text { Mampu } \\
\text { memberikan dan } \\
\text { mengubah } \\
\text { suasan dalam } \\
\text { tur menjadi } \\
\text { semarak. } \\
\text { Pemandu wisata } \\
\text { yang ada } \\
\text { mampu } \\
\text { memberikan } \\
\text { suasana yang }\end{array}$ & $\begin{array}{l}\text { Mampu } \\
\text { mendeskripsika } \\
\text { n dan membuat } \\
\text { paket wisata } \\
\text { sesuai dengan } \\
\text { tren yang ada }\end{array}$ \\
\hline \multirow[t]{2}{*}{$\begin{array}{l}\text { Leadersh } \\
\text { ip }\end{array}$} & \multirow{2}{*}{$\begin{array}{l}\text { Memiliki } \\
\text { Teknik } \\
\text { kepemimpinan } \\
\text { yang baik dan } \\
\text { tangungjawab } \\
\text { dalam } \\
\text { melaksanakan } \\
\text { program yang } \\
\text { ada dalam paket } \\
\text { wisata dengan } \\
\text { baik }\end{array}$} & \multirow{2}{*}{$\begin{array}{l}\text { Memiliki } \\
\text { Teknik } \\
\text { kepemimpinan } \\
\text { yang baik dalam } \\
\text { hal } \\
\text { mengorganisir } \\
\text { semua } \\
\text { komponen yang } \\
\text { ada dalam paket } \\
\text { wisata sehingga } \\
\text { paket wisata } \\
\text { yang dikual bisa } \\
\text { dilaksanakan } \\
\text { dengan bik di } \\
\text { lapangan }\end{array}$} & & $\begin{array}{l}\text { hangat dan } \\
\text { bersahabat } \\
\text { sehingga para } \\
\text { wisatawan } \\
\text { senang }\end{array}$ & \\
\hline & & & \multirow[t]{2}{*}{$\begin{array}{l}\text { Image } \\
\text { building }\end{array}$} & \multirow[t]{2}{*}{$\begin{array}{l}\text { Mampu } \\
\text { membangun } \\
\text { image yang } \\
\text { bagus bagi } \\
\text { perusahaan CV. } \\
\text { Gondes Karya } \\
\text { Mandiri, } \\
\text { sehingga para } \\
\text { wisatawan yang } \\
\text { pernah } \\
\text { mengikuti tur }\end{array}$} & \multirow[t]{2}{*}{$\begin{array}{l}\text { Mampu } \\
\text { membangun } \\
\text { image yang } \\
\text { bagus dalam } \\
\text { setiap membuat } \\
\text { paket wisata } \\
\text { yang dijual dan } \\
\text { mendistribusika } \\
\mathrm{n} \text { ke pemandu } \\
\text { wisata walaupun } \\
\text { ada sedikit }\end{array}$} \\
\hline Knowled & Pemandu wisata & Operator Tur & & & \\
\hline
\end{tabular}




\begin{tabular}{|c|c|c|c|}
\hline & $\begin{array}{l}\text { melakukan } \\
\text { "Repeat } \\
\text { Buying" }\end{array}$ & $\begin{array}{l}\text { perbedaan } \\
\text { dalam proses } \\
\text { identifikasi }\end{array}$ & $\begin{array}{l}\text { solusi yang } \\
\text { terbaik agar tur } \\
\text { berjalan lancar }\end{array}$ \\
\hline $\begin{array}{l}\text { Physical } \\
\text { appearan } \\
\text { ce }\end{array}$ & $\begin{array}{l}\text { Penampilan } \\
\text { fisik baik, } \\
\text { nyaman dilihat } \\
\text { namun tidak } \\
\text { berlebihan. }\end{array}$ & $\begin{array}{l}\text { Penampilan } \\
\text { fisik baik sesuai } \\
\text { dengan standar } \\
\text { yang ditentukan } \\
\text { perusahaan }\end{array}$ & $\begin{array}{ll}\text { Identifica } & \text { Selalu } \\
\text { tion with } & \text { berkomunikasi } \\
\text { tur } & \text { dengan baik } \\
\text { operator } & \text { dengan operator } \\
& \text { tur agar tur } \\
& \text { berialan sesuai }\end{array}$ \\
\hline \multirow{2}{*}{$\begin{array}{l}\text { Contract } \\
\text { complian } \\
\text { ce }\end{array}$} & \multirow{2}{*}{$\begin{array}{l}\text { Taat terhadap } \\
\text { perjanjian yang } \\
\text { dibuat sesuai } \\
\text { dengan jabaran } \\
\text { kinerja yang } \\
\text { diberika pihak } \\
\text { operator tur }\end{array}$} & \multirow[b]{2}{*}{$\begin{array}{l}\text { Memberikan } \\
\text { kontrak kerja } \\
\text { sama dan } \\
\text { menjelaskan } \\
\text { secara detail } \\
\text { kontrak maupun } \\
\text { tugas dan } \\
\text { tanggungjawab } \\
\text { dari pemandu } \\
\text { wisata }\end{array}$} & \\
\hline & & & $\begin{array}{l}\text { Mampu } \\
\text { berkomunikasi } \\
\text { dan } \\
\text { berkorrdinasi } \\
\text { dengan baik } \\
\text { dan } \\
\text { menyebarkan } \\
\text { informasi } \\
\text { terbaik yang }\end{array}$ \\
\hline \multirow[t]{2}{*}{$\begin{array}{l}\text { Itinerary } \\
\text { complian } \\
\text { ce }\end{array}$} & \multirow{2}{*}{$\begin{array}{l}\text { Patuh terhadap } \\
\text { itinerary yang } \\
\text { dibuat oleh } \\
\text { operator tur dan } \\
\text { selalu } \\
\text { berkoordinasi } \\
\text { dengan operator } \\
\text { tur jika terjadi } \\
\text { kendala } \\
\text { dilapangan }\end{array}$} & \multirow{2}{*}{$\begin{array}{l}\text { Taat terhadap } \\
\text { kontrak } \\
\text { kesepakan yang } \\
\text { dibuat dengan } \\
\text { pemandu wisata } \\
\text { dan selalu } \\
\text { memberikan } \\
\text { koordinasi yang } \\
\text { baik jika ada } \\
\text { masalah } \\
\text { dilapangan } \\
\text { dengan } \\
\text { pemandu wisata }\end{array}$} & $\begin{array}{l}\text { berkaitan } \\
\text { dengan BPW }\end{array}$ \\
\hline & & & $\begin{array}{l}\text { Sumber : CV Gondes Karya Mandiri } \\
\text { Sinergitas antara pemandu wisata dengan } \\
\text { operator Tur dari berbagai karakteristik, } \\
\text { atribut serta perspektif pemandu wisata } \\
\text { maupun Operator Tur. Hasil penelitian } \\
\text { menemukan bahwa perbedaan persepsi } \\
\text { pemandu dan operator tur tentang } \\
\text { karakteristik ini juga dieksplorasi dan } \\
\text { dibahas terutama berkaitan dengan kualitas } \\
\text { pribadi Keteramnilan komunikasi. }\end{array}$ \\
\hline $\begin{array}{l}\text { Problem- } \\
\text { solving }\end{array}$ & $\begin{array}{l}\text { Mampu } \\
\text { memberikan } \\
\text { jalan keluar } \\
\text { terbaik jika } \\
\text { terjadi kendala } \\
\text { dilapangan. } \\
\text { Kendala } \\
\text { dilapangan } \\
\text { sering tidak } \\
\text { terduga dan } \\
\text { butuh } \\
\text { penanganan } \\
\text { yang segera agar } \\
\text { wisatawan } \\
\text { nyaman dan tur } \\
\text { bisa berjalan } \\
\text { dengan lancar }\end{array}$ & $\begin{array}{l}\text { Memberikan } \\
\text { dukungan dan } \\
\text { bantuan jika } \\
\text { pemandu wisata } \\
\text { mendapatkan } \\
\text { kendala maupun } \\
\text { permasalah } \\
\text { dilapangan } \\
\text { dengan } \\
\text { memberikan } \\
\text { solusi yang } \\
\text { cepat dan } \\
\text { bertanggungjaw } \\
\text { ab. Biasanya } \\
\text { koordinasi } \\
\text { dilakukan } \\
\text { dengan baik } \\
\text { melalui berbagi } \\
\text { media. } \\
\text { Dukungan } \\
\text { diberikan } \\
\text { selama ada } \\
\text { kendala dan } \\
\text { memberikan } \\
\end{array}$ & $\begin{array}{l}\text { penyebaran informasi dan pengetahuan } \\
\text { yang canggih menerima peringkat tertinggi } \\
\text { dari kedua kelompok responden. Hasil } \\
\text { tersebut sejalan dengan fakta dilapangan } \\
\text { yang mengakui informasi dan komunikasi } \\
\text { pengetahuan sebagai peran utama } \\
\text { pemandu. Namun, pemandu dan operator } \\
\text { tur memberikan penilaian yang berbeda } \\
\text { untuk item yang berkaitan dengan peserta } \\
\text { tur dan kepuasan tamu serta citra } \\
\text { perusahaan terhadap operator tur. Seperti } \\
\text { yang telah disebutkan, semua dimensi ini } \\
\text { dinilai lebih tinggi oleh responden operator } \\
\text { tur. Kesenjangan sikap antara pemandu } \\
\text { dan operator tur dapat dikategorikan dalam } \\
\text { dua kelompok besar: (1) faktor yang } \\
\text { mempengaruhi kepuasan peserta dan (2) } \\
\text { faktor yang mempengaruhi citra operator } \\
\text { tur. Item yang mempengaruhi kepuasan } \\
\text { peserta adalah tingkat bahasa asing, } \\
\text { penciptaan pengalaman liburan, hiburan, } \\
\text { dan kohesi kelompok. Operator tur }\end{array}$ \\
\hline
\end{tabular}

ISSN: 2355-6587, e-ISSN: 2528-2220 
mengandalkan steakholder untuk mempromosikan dan menjual produk wisata destinasi sebagai satu paket.

Pemandu wisata yang termotivasi juga akan memberikan umpan balik yang berharga tentang rencana perjalanan, dari pemasok paket wisata untuk dilaksanakan dengan baik. Namun terkadang terkendala dengan situasi jalanan dan iklim yang ada dilapangan, sehingga pemandu wisata membuat perubahan dari rencana awal. Sedangkan lemahnya koordinasi disebabkan oleh regulasi yang ada sehingga dalam SOP perusahaan yang mengharuskan membuat laporan terperinci dan prosedural sehingga menghambat bagi opeartur tur untuk bisa memberikan pelayanan yang cepat, tepat dan akurat. Namun sejauh ini peran dari pemandu wisata dan operator tur dapat berjalan dan bekerjasama dengan baik sehingga paket wisata yang dilaksanakan dapat berjalan dengan lancar serta minim komplain dari para wisatawan yang dibawa.

\section{PENUTUP}

Sinergitas Antara Pemandu Wisata Dan Operator Tur berjalan dengan baik dalam bentuk paket wisata dengan pilihan harga maupun fasilitas yang bervariasi sehingga program dan pelaksanaan wisata dapat berjalan dengan lancar. Peningkatakan kemampuan dan kompetensi yang dikuasai harus ditingkatkan lagi agar mampu memberikan pelayanan yang lebih baik lagi. Selain itu masih diperlukan tingkat pembeda pada penerimaan hasil dan sistem penggajian sehingga tidak ada kecemburuan sosial dalam melaksanakan pekerjaan yang sesuai dengan ketentuan- ketentuan yang berlaku diperusahaan. Diharapkan penlitian selanjutnya dapat meneliti dengan variable yang berbeda dengan fokus pemanduan agar dapat digunakan sebagai acuran dalam kegiatan dilapangan.

\section{REFERENSI}

Cohen, E. H., Ifergan, M., \& Cohen, E. (2002). A new paradigm in guiding: The Madrich role model. Annals of Tourism Research, 22(4), 818-932. doi:10.1016/S0160-7383(01)00082-2
Dahles, H. (2002). The politics of tour guiding: Image management in Indonesia. Annals of Tourism Research, 29(3), 783-800. doi:10.1016/S0160-7383(01)00083-4

Federasi Asosiasi Pemandu Wisata Dunia: 2014

Hansen, A. H., \& Mossberg, L. (2016). Tour guides' performance and tourists' immersion: Facilitating consumer immersion by performing a guide plus role. Scandinavian Journal of Hospitality and Tourism, 1-20. (in press).

Huang, S., Hsu, C. H. C., \& Chan, A. (2010). Tour guide performance and tourist satisfaction: A study of the package tours in Shanghai. Journal of Hospitality and Tourism Research, 34(1), 3-33. doi:10. $1177 / 1096348009349815$

Jonasson, M., \& Scherle, N. (2012). Performing co-produced guided tours. Scandinavian Journal of Hospitality and Tourism, 12(1), 55-73. doi:10.1080/15022250.2012.655078

Larsen, J., \& Meged, J. W. (2013). Tourists co-producing guided tours. Scandinavian Journal of Hospitality and Tourism, 13(2), 88-102. doi:10.1080/15022250.2013.796227

Mak, A. H. N., Wong, K. K. F., \& Chang, C. Y. (2011). Critical issues affecting the service quality and professionalism of the tour guides in Hong Kong and Macau. Tourism Management, 32, 1442-1452. doi:10.1016/j.tourman.2011.01.003Tjip tono $(2014: 268)$

\section{BIODATA PENULIS}

I Putu Hardani Hesti Duari adalah Dosen Tetap pada Program Studi Usaha Perjalanan Wisata, Sekolah Tinggi Pariwisata AMPTA Yogyakarta. Memiliki kepakaran di bidang Usaha Perjalanan Wisata, ilmu ticketing penerbangan serta pemanduan wisata. Mengajar bidang Usaha Perjalanan Wisata sekaligus sebagai asesor pemanduan wisata serta penulis buku Usaha Perjalanan Wisata baik tingkat Akademisi maupun tingkat SMK UPW. 